\title{
Taşıt Titreşimlerinin Sürücü Konforuna Etkisi: Yarım Araba ve Sürücü Modeli
} Effect of Vehicle Vibrations on the Driver Comfort: Half Car and Driver Model

\author{
Mithat YANIKÖREN*,a ${ }^{1, \text { Selim TEZGEL }}{ }^{2, \mathrm{~b}}$, Bilal USANMAZ ${ }^{3, \mathrm{c}}$, Ömer GÜNDOĞDU $^{4, \mathrm{~d}}$ \\ ${ }^{1}$ Bilecik Şeyh Edebali Üniversitesi, Meslek Yüksekokulu, Mekatronik Programı, 11230, Bilecik \\ ${ }^{2}$ Gümüşhane Üniversitesi, Mühendislik ve Doğa Bilimleri Fakültesi, Makine Mühendisliği Bölümü, 29100, Gümüşhane \\ ${ }^{3}$ Atatürk Üniversitesi, Mühendislik Fakültesi, Bilgisayar Mühendisliği Bölümü, 25240, Erzurum \\ ${ }^{4}$ Atatürk Üniversitesi, Mühendislik Fakültesi, Makine Mühendisliği Bölümü, 25240, Erzurum
}

• Geliş tarihi / Received: 27.04.2020 • Düzeltilerek geliş tarihi / Received in revised form: 14.06.2020 • Kabul tarihi / Accepted: 20.06 .2020

Öz

$\mathrm{Bu}$ çalışmada taşıt titreşimlerinin sürücü konforuna etkisi, iç organlara iletilen titreşimin büyüklükleri cinsinden incelenmiştir. Bu maksatla bir yarım araba modeli, araç koltuğu ile sürücünün iç organlarıyla birlikte oluşturulmuştur. Araç ve koltuğu 5 serbestlik derecesine sahipken sürücü 4 serbestlik derecesine sahip tasarlanmış, sonuçta toplam 9 serbestlik dereceli bir sistem kurgulanmıştır. Hareket denklemleri yazılarak yollarda hız engelleyici olarak kullanılan kasisler titreşim girdisi olarak kabul edilmiştir. Farklı taşıt hızları ve farklı kasis boyutları için benzetimler yapılmış ve sürücünün başına, iç organlarına ve sürücü koltuğuna iletilen titreşimler incelenmiştir. İç organlara iletilen titreşimlerin büyüklükleri değerlendirilirken kök ortalama kare (RMS) değerleri kullanılmış ve sonuçlar grafikler vasıtasıyla yorumlanmıştır. Literatürde süspansiyon ve sürücü koltuk tasarımları daha çok sürücü koltuğuna iletilen titreşimin azaltılmasını kıstas alırken çok azı ise sürücü kafasına iletilen titreşimin ivmesi esas almaktadır. Bu çalışmada ise süspansiyon, koltuk ve kasis tasarımlarında sürücünün hem başı hem de iç organlarına iletilen titreşimin kök ortalama kare değerinin de hesaba katılması önerilmiştir.

Anahtar kelimeler: Biyotitreşim, İç Organ Titreşimi, Kasis, Tüm Vücut Titreşimi, Yarım Araba

\begin{abstract}
In this study, the effects of vehicle vibrations on driver comfort are examined in terms of the magnitude of the vibration transmitted to the internal organs. For this purpose, a half car model was created with the vehicle seat and the driver with the internal organs. While the vehicle and its seat have 5 degrees of freedom, the driver is modeled as 4 degrees of freedom, and as a result, a system with a total of 9 degrees of freedom has been modeled. The bumps used as speed regulators on the roads are accepted as vibration input to the system while writing the equations of motion. Simulations were performed for different vehicle speeds and different bumper dimensions to evaluate the vibrations transmitted to the driver's head, internal organs and the driver's seat. When assessing the magnitudes of the vibrations transmitted to the internal organs, the root mean square is used. In the literature, suspension and driver seat designs take the criterion of reducing the vibration transmitted to the driver's seat, while few are based on the acceleration of the vibration transmitted to the driver's head. In this study, it is proposed to take into account the root mean square value of the vibration transmitted to both the head and internal organs of the driver in suspension, seat and bump designs.
\end{abstract}

Keywords: Biovibration, Viscera Vibration, Speed Bump, Whole Body Vibration, Half Car

\footnotetext{
*a Mithat YANIKÖREN; mithat.yanikoren@bilecik.edu.tr, Tel: (0228) 21424 18, orcid.org/ 0000-0003-1075-313X

${ }^{b}$ orcid.org/0000-0003-2153-4071 $\quad{ }^{c}$ orcid.org/0000-0003-0531-4618_ orcid.org/0000-0003-2656-4181
} 


\section{Giriş}

Titreşimler, sistemlerin belirli bir denge noktası etrafindaki salınıml hareketleri olarak tarif edilirler. Mekanik eleklerde olduğu gibi belirli bir amaç için istemli olarak oluşturulmuyorlarsa genellikle sistemlerde bozucu etkileri vardır ve tasarımcılar tarafından engellenmeye çalışılırlar. Titreşim kontrolünde genellikle gürültüyü, yıpranmayı ve yorulmayı engellemenin yanında insan konforunu sağlama amaçlanır.

Sistem titreşimlerinin yanı sıra insanlar da günlük yaşamlarında birçok titreşime maruz kalırlar. Örneğin bir araçla seyahat eden veya bir aleti/iş makinasını kullanan bir insan da birtakım sarsıntılara maruz kalır. Bu titreşimlerin; tarım aracı süren veya iş makinası kullanan bir insanın durumunda olduğu gibi bir bütün olarak vücuduna aktarılmasına 'tüm vücut titreşimi' ve el testeresi gibi aletleri kullananların el ve kollarına iletilen titreşimlere de 'el-kol titreşimleri' olarak tanımlanır (Mansfield, 2004).

İnsan vücudunu etkileyen titreşimler öncelikle vücudun eklemlerle bağlı olan bölümlerinin (kollar, bacaklar, baş, omurilik vb.) düzgün çalışmamasını etkiler. Bunlara bağlı olarak eklem ağrıları, bel ağrıları, meslek hastalıkları, sinir sistemi bozuklukları gibi rahatsızlıklar meydana gelir. Ayrıca uzun süreli titreşime maruz kalan vücudun duruşunda ve dengesinde bozulmalar meydana gelir. Tüm bu etkilere bağlı olarak istenmeyen psikolojik, sosyolojik gibi ikincil rahatsılıklar meydana gelir (Maioh, 2007).

Literatürde, çok sayıda çeyrek, yarım ve tam araba modellerinin yanı sira arabanın koltukla ve/veya sürücüsüyle birlikte titreşim model ve benzetimleri ile optimizasyonlarını bulmak mümkündür. Burada konuyla ilgili birkaç yayından bahsedilmekle yetinilecektir. Gündoğdu (2007), Özellikle insan vücudunun titreşimlerini göz önüne alarak süspansiyon tasarımının en iyilemesinin yaptığı bir çalışmada, çeyrek arabayı, koltuk ve insan vücuduyla birlikte modellemiş ve sürücü konforunu arttıracak en iyi süspansiyon parametrelerini tespit etmeye çalışmıştır. Mitra vd. (2016) ise standartlara göre sürüş konforunun iyileştirebilmek için temel ve basit bir 4 serbestlik dereceli çeyrek araç modelin matematiksel denklemlerini modal analiz yöntemi kullanılarak çıkarmışlar ve SIMULINK kullanılarak benzetimini yapmışlardır. Sürücü konforunu en iyilemek için de genetik algoritmalardan faydalanarak yay katsayısı, sönüm katsayısı, ask1 kütlesi, aks kütlesi ve tekerlek yaylanma katsayılarını bulmuşlardır. Nagarkar vd. (2016) yaptıkları çalışmada, sürücü modeli ile lineer olmayan çeyrek oto koltuğu süspansiyon sisteminin çok amaçlı en iyilemesini sunmuşlardır. Lastikte ve süspansiyonda doğrusal olmayan yaylar kullanılarak kurulan çeyrek araba ile sürücünün modeli 8 serbestlik derecesine sahiptir. Çok amaçlı optimizasyonlarında; kafa hızlanmas1, kafa RMS (Root Mean Square-Kök Ortalama Kare) hizlanmasinin koltuk RMS hızlanmasına genlik oranı, üst gövde RMS hızlanmasının koltuk RMS hızlanmasına genlik oran1, tepe faktörü, süspansiyon dinamik sapma açısından ve dinamik lastik kuvveti büyüklüklerini optimizasyonun amaç fonksiyonları olarak kabul ederek problemlerini çözmüşlerdir. Benzetim sonucunda, optimum tasarım değişkenlerinin klasik tasarım değişkenlerine göre sürüş konforunu ve sağlık kriterlerini iyileştirdiğini göstermişlerdir.

Liand vd. (2007), yol bozuklukları nedeni ile dikey titreşime maruz kalan hamile sürücülere veya yolculara etkilerini inceleyen yarım araç modeli ve tam araç modeli önermişlerdir. Gadhvi vd. (2016) yaptıkları çalışmada, yarım arabanın pasif süspansiyon sistemini en iyilemek için kısıtlanmış çok amaçlı bir optimizasyon çalışması yapmışlardır. Tasarım değişkenleri; sürücü koltuğu ile ön ve arka süspansiyonların direngenlik ve sönümleme sabitleridir. Amaç fonksiyonu olarak; sürücü koltuğunun sürüş konforunun iyileştirilmesi, ön lastik ve yol arasındaki dinamik kuvvetin değişimini (veya ön lastik sapmasını) en aza indirgemek ve arka lastikte benzer şekilde daha iyi yol tutuşu sağlamayı amaçlamışlardır. Konuyla ilgili olarak Anandan ve Kandavel (2020), sürücü ve yolcunun da dahil olduğu 14 serbestlik dereceli bir yarım araç modeli önermiş ve sürüş konforunu artırmak için aktif süspansiyon sistemi araca entegre edilmiştir. Geliştirilen bu model ile farklı araç hızları altında çeşitli yol profillerinde simülasyon sonuçları incelenmiş ve pasif süspansiyon sistemi ile karşılaştırılmıştır. Sürücü ve yolcu vücut ivmelenmesi (kafa titreşimi), aracın dikey kütle ivmelenmesi, ön ve arka süspansiyon sapması, ön ve arka lastik sapması gibi ilgili performans ölçütleri benzetilmiştir. Simülasyon sonuçları önerilen aktif süspansiyon sisteminin araç dengesi ve sürüş güvenliği ile sürüş konforunu önemli ölçüde artırdığını göstermişlerdir.

$\mathrm{Bu}$ çalışmada, karayollarında kullanılan kasislerin (hız kesicilerin) tüm vücut titreşimlerine ve özellikle insan iç organlarına ve kafasına etkisi incelenmiştir. Standartlarda insan kafasının maruz 
kaldığı titreşimler esas alınırken iç organlara etkisine -bazı çalışmalarda incelenmesine rağmen- yeterince önem verilmediği görülmüsşür. $\mathrm{Bu}$ çalışmada koltuğuyla birlikte bir yarım arabanın modeli, kafa ve iç organları da içeren bir insan modeliyle birlikte kurulmuş ve karayollarında kullanılan kasislerin etkisi titreşim açısından incelenmiştir.

\section{Gereç ve Yöntem}

\subsection{Fiziksel Model}

Çalışmada kullanılan model, mekanik sistem elemanlarının (yay, kütle ve amortisör) kullanıldığı bir biyotitreşim modelidir. Yarım araba üzerine monte edilmiş bir koltuk üzerinde oturan sürücünün kafasına ve iç organlarına iletilen titreşim, 9 serbestlik dereceli bir model kurularak incelenmiştir.
Araba, Şekil 1'de gösterildiği gibi yarım araba modeli şeklinde düşünülmüş ve üzerine bir sürücü koltuğu yerleştirilmiştir. Tekerlekler ise ön ve arka çiftler birlikte modellenmiştir. Bu şekliyle araba 5 serbestlik derecesine sahip olup arabaya ait ağırlık, atalet, yay sabiti ve sönüm sabitleri gibi değerler literatürden alınmıştır (Abbas vd, 2013). Bu parametreler Tablo 1'de gösterilmiştir.

İnsan vücudu ise oturur vaziyette ve 4 serbestlik derecesine sahip bir model olarak geliştirilmiştir (bkz. Şekil 1). Model, insan kafasına ve iç organlarına yoldaki kasis sebebiyle iletilecek titreşimleri yansitacak şekilde seçilmiştir. Modelle ilgili yay, kütle ve sönüm sabitleri literatürden alınmıştır (Wan ve Schimmels, 1995). Bu parametreler Tablo 2'de listelenmiştir.

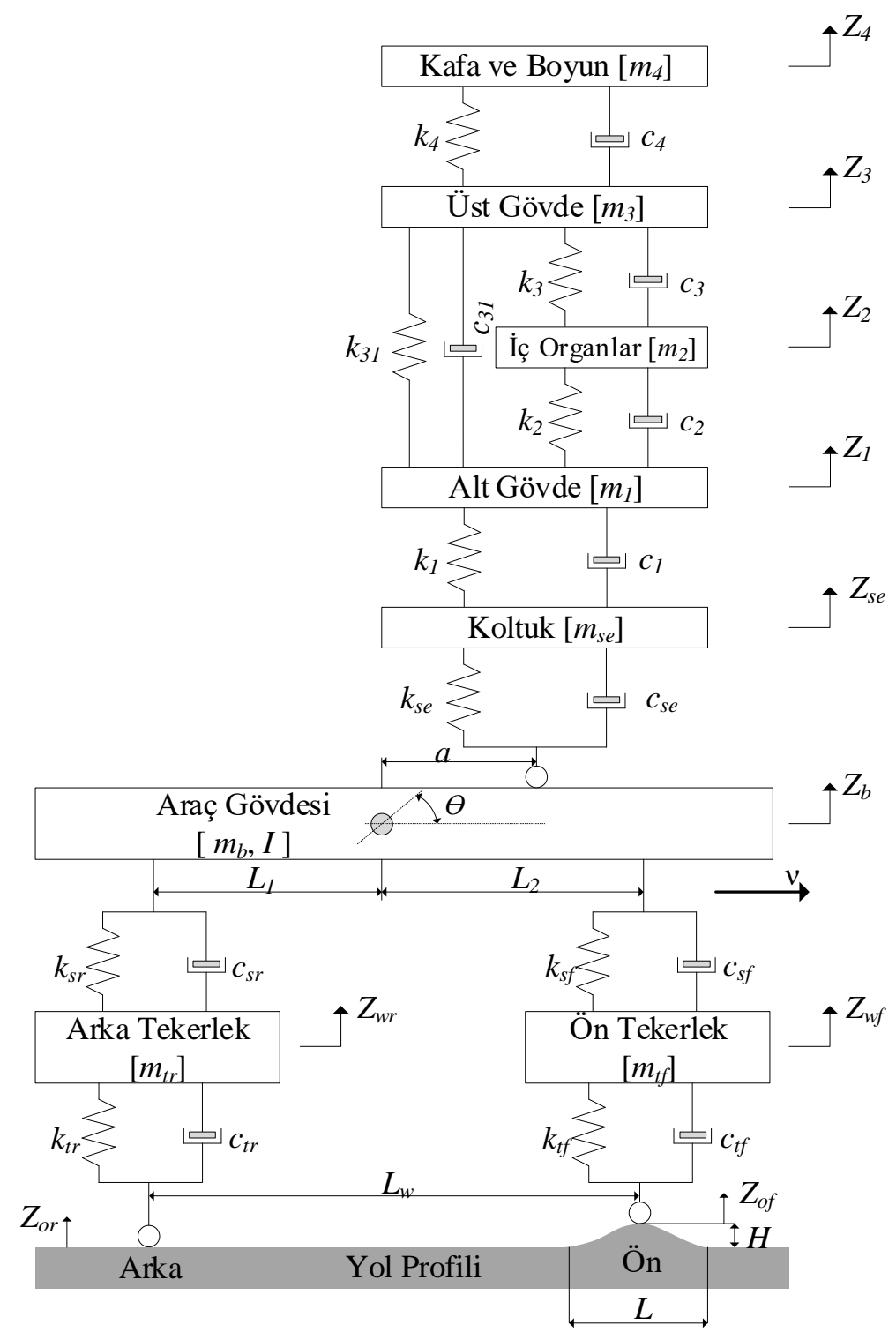

Şekil 1. Taşıt ve sürücüye ait fiziksel model 
Tablo 1. Yarım araç ve koltuk süspansiyon model parametreleri (Abbas vd, 2013)

\begin{tabular}{lcc}
\multicolumn{1}{c}{ Parametre } & Sembol & Değer \\
\hline Ön lastik yay katsayısı (N/m) & $k_{t f}$ & 155 \\
Arka lastik yay katsayısı (N/m) & $k_{t r}$ & 900 \\
Ön aks kütlesi (Kg) & $m_{w f}$ & 28.58 \\
Arka aks kütlesi (Kg) & $m_{w r}$ & 54.3 \\
Ön ve arka süspansiyon sönümleme katsayısı (Ns/m) & $c_{s f}, c_{s r}$ & 1828 \\
Ön ve arka lastik sönümleme katsayısı (Ns/m) & $c_{t f}, c_{t r}$ & 0 \\
Ön ve arka süspansiyon yay katsayısı (N/m) & $k_{s f}, k_{s r}$ & 15000 \\
Ön aks ile araç ağırlık merkezi arasındaki mesafe (m) & $L_{1}$ & 1.098 \\
Arka aks ile araç ağırlık merkezi arasındaki mesafe $(\mathrm{m})$ & $L_{2}$ & 1.468 \\
Koltuk ve araç ağırlık merkezi arasındaki mesafe $(\mathrm{m})$ & $a$ & 0.7 \\
Araç gövde kütlesi (Kg) & $m_{b}$ & 505.1 \\
Araç gövdesinin kütle atalet momenti (Kgm $\left.{ }^{2}\right)$ & $I$ & 651 \\
Koltuk Kütlesi (Kg) & $m_{s e}$ & 35 \\
Koltuk sönümleme katsayısı (Ns/m) & $c_{s e}$ & 150 \\
Koltuk süspansiyon yay katsayısı (N/m) & $k_{s e}$ & 15000 \\
\hline
\end{tabular}

Tablo 2. Oturan sürücü biyomekanik parametreleri (Wan ve Schimmels, 1995)

\begin{tabular}{cccccc}
\hline & \multicolumn{2}{c}{ Kütle (Kg) } & \multicolumn{2}{c}{ Sönümleme Katsayısı (Ns/m) } & \multicolumn{2}{c}{ Yay Katsayısı (N/m) } \\
\hline$m_{1}$ & 36 & $c_{1}$ & 2475 & $k_{1}$ & 49340 \\
$m_{2}$ & 5.5 & $c_{2}$ & 330 & $k_{2}$ & 20000 \\
$m_{3}$ & 15 & $c_{3}$ & 200 & $k_{3}$ & 10000 \\
$m_{4}$ & 4.17 & $c_{4}$ & 250 & $k_{4}$ & 134400 \\
& & $c_{31}$ & 909.1 & $k_{31}$ & 192000
\end{tabular}

\subsection{Matematiksel Model ve Simülasyon}

Fiziksel modeli yukarıda izah edilen araç ve sürücü sisteminin matematiksel modeli NewtonEuler formülasyonu kullanılarak elde edilmiştir. Araba kütlesi hariç tüm kütleler maddesel nokta yaklaşımı ile ifade edildiğinden

$\sum F_{z, i}=m_{i} \ddot{z}_{i}$

formülünü kullanmak yeterlidir. Ancak araba gövdesi bir rijit cisim olarak modellendiğinden, Denklem (1) ile birlikte

$\sum M_{G}=I_{G} \ddot{\theta}$

moment denklemi de kullanılmalıdır. Böylece, elde edilen matematiksel ifadeler, 9 adet sabit katsayılı ikinci mertebeden doğrusal adi diferansiyel denklemdir. $\mathrm{Bu}$ denklemler, genel formu

$\dot{\mathbf{x}}=\mathbf{A x}+\mathbf{B u}$

$\mathbf{y}=\mathbf{C x}+\mathrm{Du}$ ile durum uzayları biçiminde yazılmıştır. $\mathrm{Bu}$ denklemler, yukarıda bahsedilen 9 diferansiyel denklemin ara değişkenler kullanılarak 18 adet birinci mertebe diferansiyel denklemleriyle yeniden ifade edilmesidir. Burada (3) denklemiyle gösterilen sistemin matematiksel modelini temsil ederken (4) denklemiyle çıtılar kurgulanmıştır.

Sistem denklemindeki $\mathbf{x}$ ve $\mathbf{y}$ sirasıly durum ve çıtı vektörleridir. A ve $\mathbf{B}$ matrisleri sırasıyla durum (veya sistem) ve girdi (veya input) matrisleridir. C ve D matrisleri ise sırasılyla çıktı (veya output) ve ileri (veya geri) besleme matrisleridir.

Çıktılar, sürücü başının $\left(a_{4}\right)$ ve iç organlarının ivmeleri $\left(a_{2}\right)$ ile sürücü koltuğunun titreşimlerini elde edecek şekilde düzenlenmiştir.

Durum uzaylarında yazılan bu denklemler MATLAB $^{\mathbb{B}}$ de kodlanmış ve benzetimler gerçekleştirilmiştir. Diferansiyel denklemleri çözmek için MATLAB ${ }^{\circledR}$ de hazır bulunan ode45 komutu kullanılmıştır. 
Sinüzoidal biçiminde verilen

$z_{o f}=H \sin \left(\frac{\pi v}{L} t\right)$

$z_{\text {or }}=H \sin \left(\frac{\pi v}{L}(t+\tau)\right)$

yol profiline karşı sistemin verdiği cevaplar, kasis eni ve yüksekliğine karşı benzetimleri yapılmıştır.

\section{Bulgular}

Benzetim sonuçları, ilk olarak belirli bir taşıt hızı $(v=30 \mathrm{~km} / \mathrm{sa})$, kasis genişliği $(L=40 \mathrm{~cm})$ ve kasis yüksekliği $(H=5 \mathrm{~cm})$ için alınmış ve Şekil 2-4'te sunulmuştur.

Şekil 2'de, yukarıda verilen şartlar altında kasisten geçen bir arabanın sürücüsünün başına etkiyen ivme $\left(a_{4}\right)$ sunulmuştur. Şekil üzerinde taşıtın kasise ilk çarptığında oluşan düşük frekanslı titreşimler açıkça gözlenmektedir. Şekil 3'te ise benzer şekilde yukarıda verilen şartlar altında kasisten geçen bir arabanın sürücüsünün iç organlarına etkiyen ivme $\left(a_{2}\right)$ sunulmuştur. Şekil 4 'te ise bu şartlar altında araba koltuğuna etkiyen titreşimler $\left(z_{s e}\right)$ gösterilmiştir.

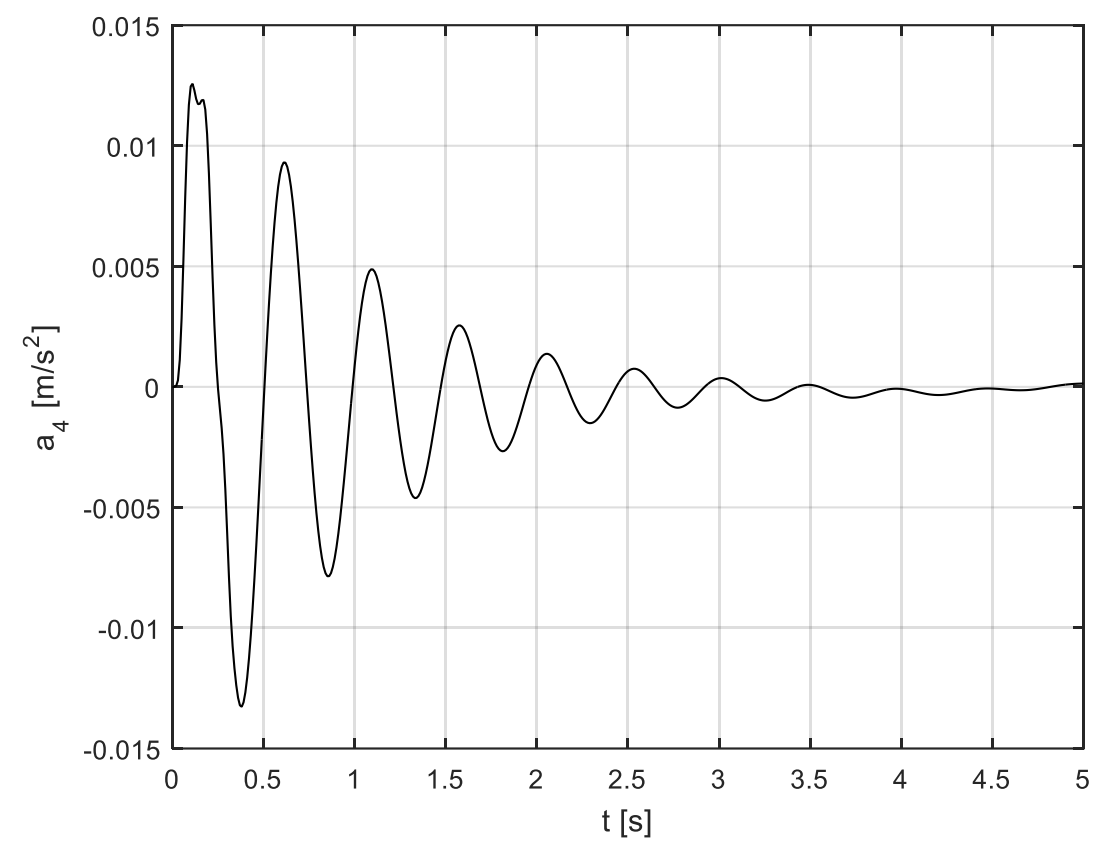

Şekil 2. Sürücü başının maruz kaldığı ivme ( $v=30 \mathrm{~km} / \mathrm{sa}, L=40 \mathrm{~cm}, H=5 \mathrm{~cm})$

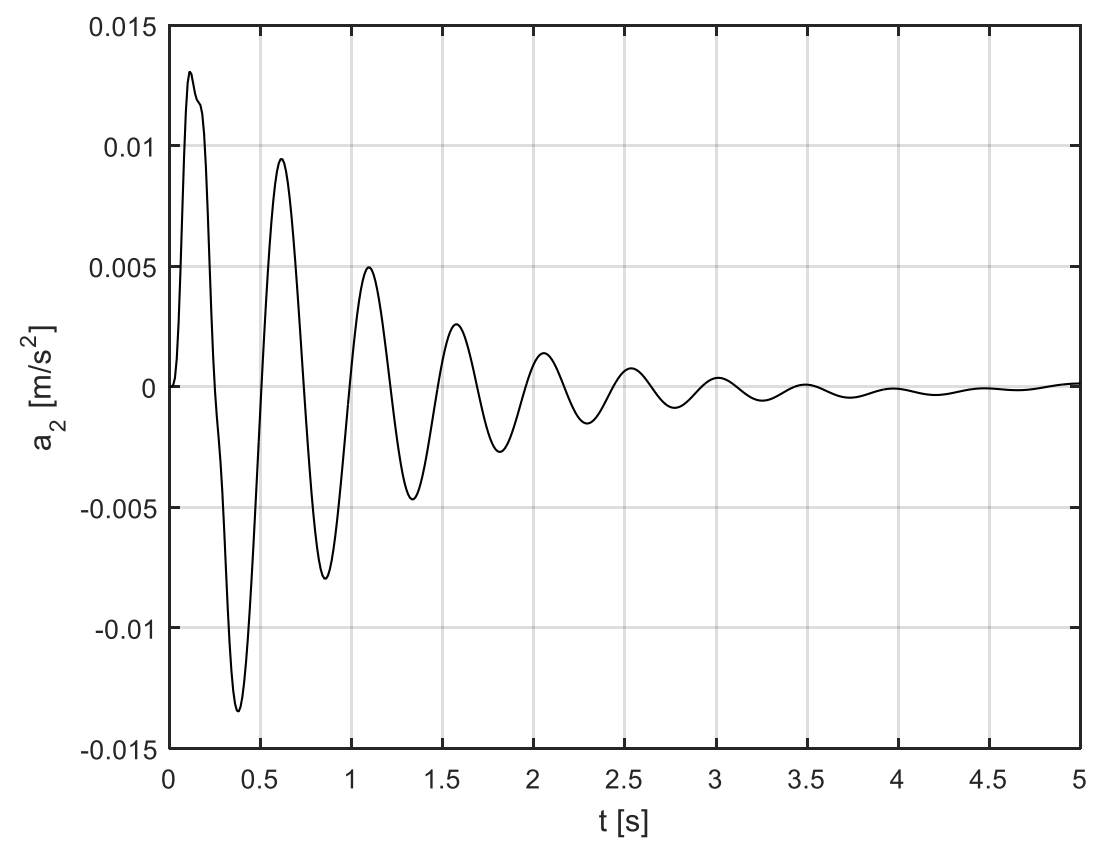

Şekil 3. Sürücü iç organlarının maruz kaldığ 1 ivme $(v=30 \mathrm{~km} / \mathrm{sa}, L=40 \mathrm{~cm}, H=5 \mathrm{~cm})$ 


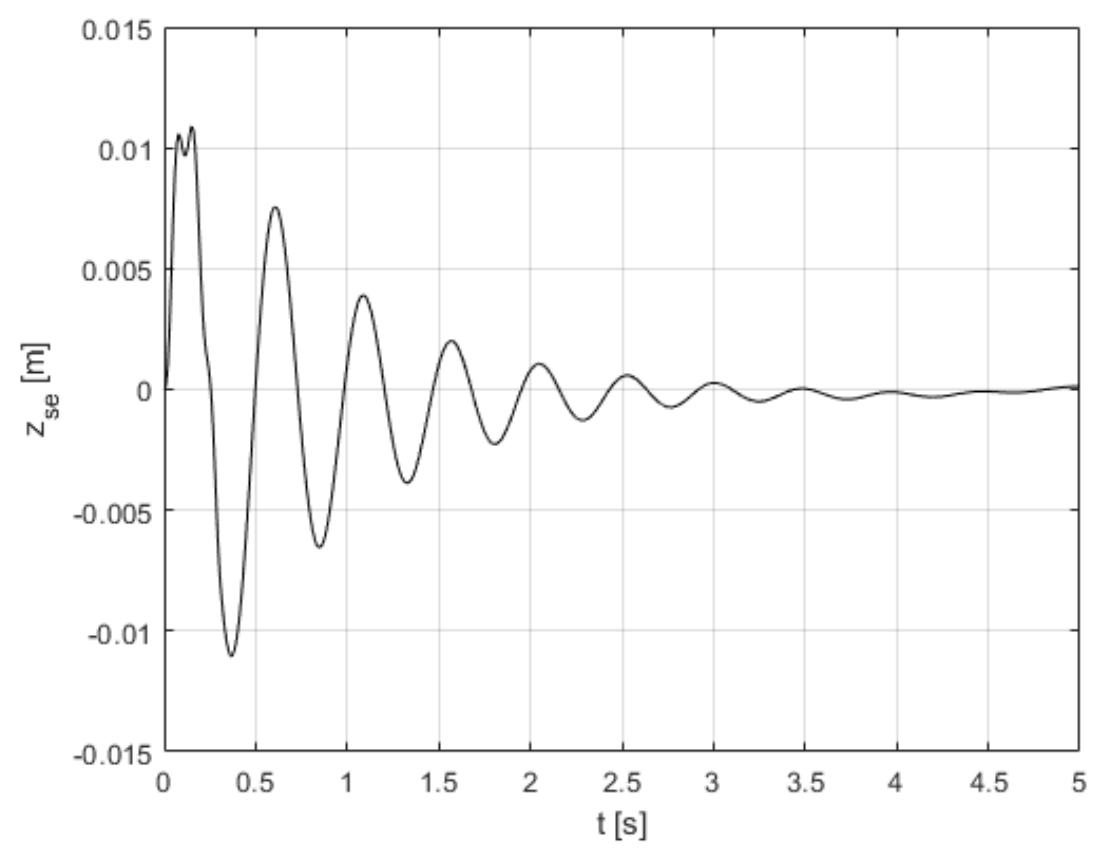

Şekil 4. Sürücü koltuğunun maruz kaldığ titreşimler ( $v=30 \mathrm{~km} / \mathrm{sa}, L=40 \mathrm{~cm}, H=5 \mathrm{~cm})$

Yukarıda sunulan belirli bir taşıt hızı ile belirli kasis genişliği ve yüksekliği yerine bir seri taşıt hızı $(5 \leq v \leq 60 \mathrm{~km} / \mathrm{sa})$, kasis yüksekliği $(1 \leq$ $H \leq 20 \mathrm{~cm})$ ve kasis genişliği $(\mathrm{L}=40 \mathrm{~cm})$ için benzetimler tekrarlanmıştır. $\mathrm{Bu}$ üç değişkenden birinin tesiri incelenirken diğer ikisi sabit tutulmuştur.

$\mathrm{Bu}$ değişimlerin tesirini gözlemleyebilmek maksadıyla sürücü iç organlarına gelen ivmelerin RMS değerleri (7) denklemine göre hesaplanarak grafikler halinde Şekil 5-6'de sunulmuştur.
$R M S(a)=\sqrt{\frac{1}{T} \int_{0}^{T} a^{2}(t) d t}$

İvmelenmenin ortalaması sinyalin büyüklüğünü göstermeyeceği için RMS kullanılmıştır. Denklem (7) de $a$ ivmelenmeyi, $\mathrm{T}$ ise periyodu ifade etmektedir.

Şekil 5'te, kasis boyutları sabit tutulurken hız değiştirilmiş ve sürücünün iç organlarına iletilen titreşimin RMS değerleri hesaplanmıştır. Şekil 6'da, hız ve kasis genişliği sabit tutulmuş, kasis yüksekliğinin tesiri RMS değeri olarak gösterilmiştir

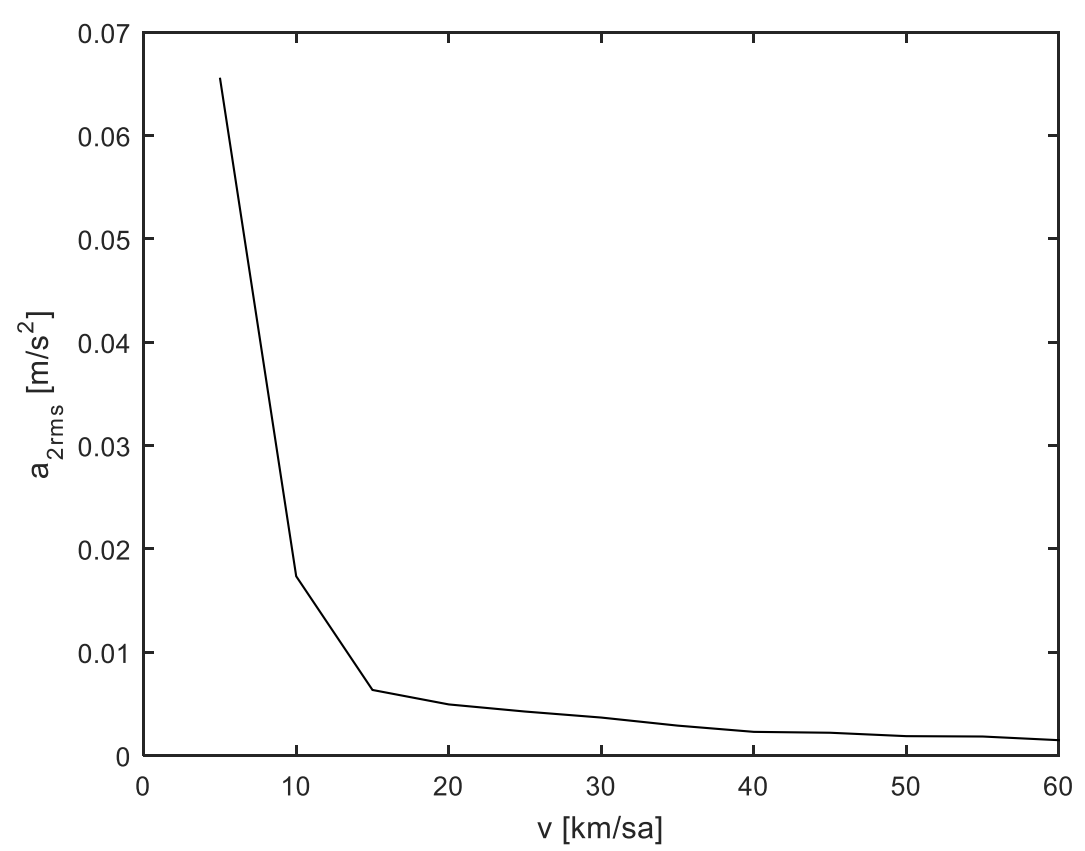

Şekil 5. Taşıt hızının iç organ titreşimlerinin RMS değerine tesiri $(L=40 \mathrm{~cm}, H=5 \mathrm{~cm})$ 


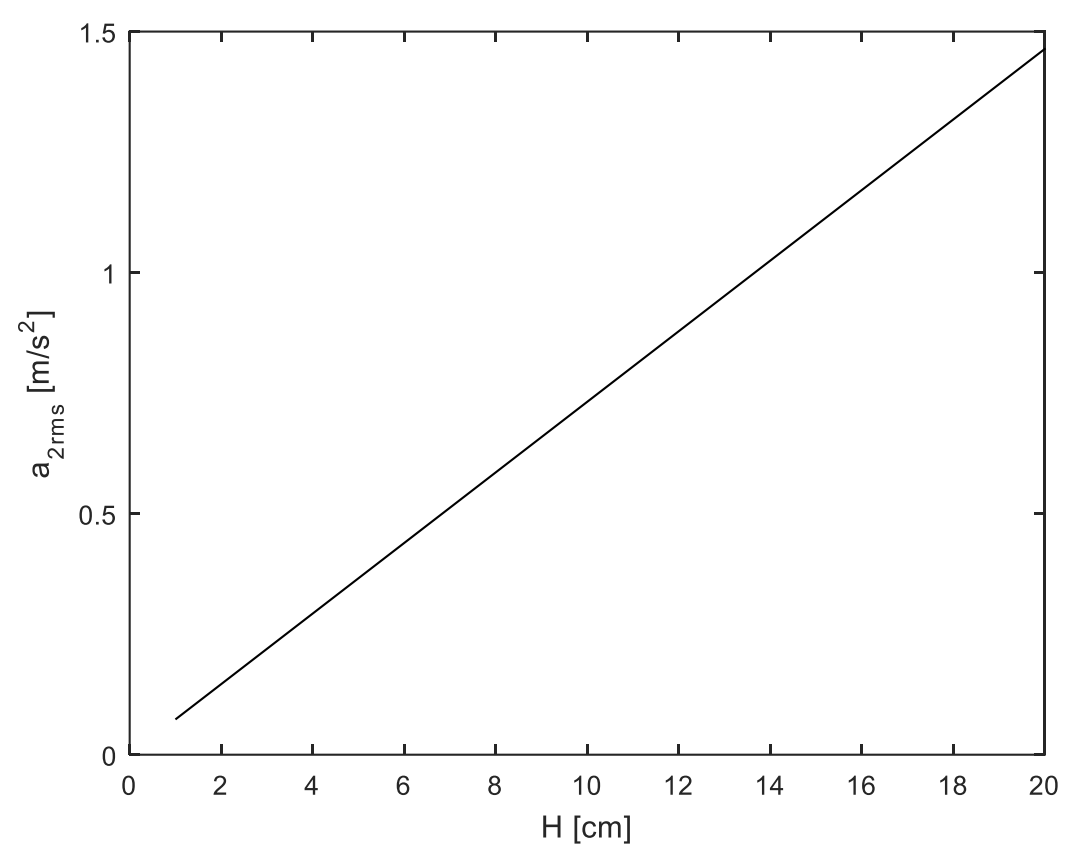

Şekil 6. Kasis yüksekliğinin iç organ titreşimlerinin RMS değerine tesiri $(v=30 \mathrm{~km} / \mathrm{sa}$, $L=40 \mathrm{~cm}$ )

\section{Tartışma ve Değerlendirme}

$\mathrm{Bu}$ çalışmada bir yarım araba titreşim modeli, sürücü koltuğu ile sürücüyü iç organlarını da içerecek şekilde kurulmuş ve yoldan gelen titreşimlerin sürücü başına ve iç organlarına iletimi benzetim yoluyla tespit edilmeye çalışılmıştır. Yol kaynaklı titreşim girdilerine örnek olarak farklı hızlarda farklı boyutlardaki sinüzoidal kasisler alınmıştır.

Yapılan benzetimler sonucunda; taşıt hızının iç organlardaki titreşime tesirinin hız arttıkça azaldığı gösterilmiştir. Bu, ilk bakıştaki algıya ters olmasına rağmen anlaşılabilir bir durumdur. Çünkü süspansiyon modeli, düşey yöndeki amortisör açıklığ 1 hızının artmasıyla sönümleme kuvvetinin büyüdüğü kabulüne dayanır. Süspansiyonlarda sönüm kuvveti $F_{d}=c v$ şeklinde modellenip düşey hız arttıkça sönüm kuvvetini artırmaktadır. $\mathrm{Bu}$ da hız arttıkça sönümlemenin fazla olduğu ve iç organlara iletilen ivmenin azaldığını gösterir. Grafik dikkatle incelendiğinde bunun da çok büyük hızlara ulaşıldığında tesirinin kalmadığı görülür. Araba süspansiyonlarına aktarılan kuvvetler düşünüldüğünde, kasislere girişte saatte $30 \mathrm{~km}$ bir hızın ideal olduğu pratik sonucuna ulaşılabilir.

Yine benzetim sonuçlarından, kasis yüksekliğinin titreşimi arttırdığı görülmüştür. $\mathrm{Bu}$ açıdan kasis yüksekliklerinin aşırı olmaması tavsiye edilebilir. Bunlar da yine fiziksel sistem düşünüldügünde anlaşılabilir sonuçlardır. Kasis yükseldiği arttıkça taşıt da bu yüksekliği takip ederek bir tepki genliği verecektir.

$\mathrm{Bu}$ çalışmanın kapsamı, taşıt titreşimlerinin sürücüye, özellikle de sürücün iç organlarına tesirini incelemektir. Yol kasisleri, bu taşıt titreşimlerinin bir kaynağı olması sebebiyle incelemeye dâhil edilmiştir. Aksi hâlde kasis tasarımı bu çalışmanın kapsamı dışındadır. Bu çalışmanın odak noktası sürücü konforunun iletilen titreşimin miktarı cinsinden belirlemektir.

\section{Kaynaklar}

Abbas, W., Emam, A., Badran, S., Shebl, M., Abouelatta, O., 2013. Optimal Seat and Suspension Design for a Half-Car with Driver Model Using Genetic Algorithm. Intelligent Control and Automation. 04, 199-205.

Anandan, A. ve Kandavel, A., 2020. Investigation and Performance Comparison of Ride Comfort on The Created Human Vehicle Road İntegrated Model Adopting Genetic Algorithm Optimized Proportional İntegral Derivative Control Technique. Proceedings of the Institution of Mechanical Engineers. Part K J. Multi-Body Dyn. 146441932090668.

Gadhvi, B., Savsani, V. ve Patel, V., 2016. MultiObjective Optimization of Vehicle Passive Suspension System Using NSGA-II, SPEA2 and PESA-II. Procedia Technology. 23, 361368.

https://doi.org/10.1016/j.protcy.2016.03.038 
Gündoğdu, Ö., 2007. Optimal Seat and Suspension Design for a Quarter Car with Driver Model Using Genetic Algorithms. Int. J. Ind. Ergon. 37, 327-332.

Liang, C.-C., Chiang, C.-F. ve Nguyen, T.-G., 2007. Biodynamic responses of seated pregnant subjects exposed to Vertical Vibrations in Driving Conditions. Vehicle System Dynamics. 45, 1017-1049.

Maioh, B.G., Noise and Vibration, Principles of Occupational Health \& Hygiene: An Introduction, 6.Ed. Tillman, C., Allen \& Unwin, 2007, Sidney, Australia.

Mansfield, N. J, 2004.Human Response to Vibration. CRC Press., Boca Raton London New York Washington, D.C. ISBN 0-415-28239-X ,14p.

Mitra, A.C., Desai, G.J., Patwardhan, S.R., Shirke, P.H., Kurne, W.M.H. ve Banerjee, N., 2016.
Optimization of Passive Vehicle Suspension System by Genetic Algorithm. Procedia Engineering., International Conference on Vibration Problems 2015 144, 1158-1166

Nagarkar, M.P., Patil, G.J., Zaware, R.N., 2016. Optimization of nonlinear quarter car suspension-seat-driver model. Journal of Advanced Research. 7, 991-1007.

TS ISO 2631-1, 2013; Mekanik Titreşim ve Şok - Tüm Vücut Titreşime Maruz Kalma Değerlendirilmesi Bölüm 1: Genel Kurallar, Türk Standartları Enstitüsü, Ankara.

Wan Y ve Schimmels JM, 1995, A Simple Model that Captures the Essential Dynamics of a Seated Human Exposed to Whole Body Vibration, Advances in Bioengineering, ASME, BED 31, 333-334. 